\title{
Vascular response to biolimus A-9 eluting stent in patients with shorter and prolonged dual antiplatelet therapy: optical coherence tomography sub-study of the NIPPON trial
}

\author{
Koji Kuroda ${ }^{1} \cdot$ Toshiro Shinke $^{1} \mathbb{D} \cdot$ Hiromasa Otake $^{1} \cdot$ Hiroto Kinutani $^{1} \cdot$ Raisuke lijima $^{2} \cdot$ Junya Ako $^{3}$. \\ Hisayuki Okada ${ }^{4} \cdot$ Yoshiaki Ito $^{5} \cdot$ Kenji Ando $^{6} \cdot$ Hitoshi Anzai $^{7} \cdot$ Hiroyuki Tanaka $^{8} \cdot$ Yasunori Ueda $^{9} \cdot$ Shin Takiuchi $^{10}$. \\ Yasunori Nishida ${ }^{11}$. Hiroshi Ohira ${ }^{12} \cdot$ Katsuhiro Kawaguchi $^{13} \cdot$ Makoto Kadotani $^{14} \cdot$ Hiroyuki Niinuma $^{15}$. \\ Kazuto Omiya ${ }^{16} \cdot$ Takashi Morita $^{17} \cdot$ Kan Zen $^{18} \cdot$ Yoshinori Yasaka ${ }^{19} \cdot K^{2}$ Kji Inoue ${ }^{20} \cdot$ Sugao Ishiwata $^{21}$. \\ Masahiko Ochiai ${ }^{22}$. Toshimitsu Hamasaki ${ }^{23}$ - Kazushi Urasawa ${ }^{24}$. Toru Kataoka ${ }^{25}$ - Minoru Yoshiyama ${ }^{26}$. \\ Kenshi Fujii ${ }^{27} \cdot$ Takumi Inoue $^{28} \cdot$ Masahito Kawata $^{29} \cdot$ Hiroyoshi Yokoi $^{30} \cdot$ Masato Nakamura $^{2} \cdot$ On behalf of the \\ NIPPON investigators
}

Received: 28 November 2017 / Accepted: 26 January 2018 / Published online: 20 February 2018

(c) The Author(s) 2018. This article is an open access publication

\begin{abstract}
Dual antiplatelet therapy (DAPT) with thienopyridine and aspirin is the standard care for the prevention of stent thrombosis. However, the optimal duration and effect of the duration of DAPT on intra-stent thrombus (IS-Th) formation are unknown. The NIPPON study (Nobori Dual Antiplatelet Therapy as Appropriate Duration) was an open label, randomized multicenter, assessor-blinded, trial designed to demonstrate the non-inferiority of shorter (6-month) DAPT to prolonged (18-month) DAPT, after biolimus A9 eluting stent implantation in 3773 patients at 130 sites in Japan. Among them, 101 patients were randomly allocated for an optical coherence tomography (OCT) sub-study to assess the difference of local IS-Th formation between the two groups. In addition to standard OCT parameters, the number of IS-Th formed was counted in each target stent at 8 months. Baseline patient characteristics were not different between the 6- and 18-month groups. IS-Th was detected in $9.8 \%$ of the cases and the presence of IS-Th was not significantly different between the two groups (10.9\% in 6-month vs. $9.1 \%$ in 12 -month, $P=0.76$ ). Furthermore, the number of IS-Th formed was not significantly different between the two groups. This OCT sub-study was in line with the main NIPPON study which demonstrated the non-inferiority of 6-month DAPT to 18-month DAPT. Shorter DAPT duration did not promote progressive IS-Th formation at the mid-term time point.
\end{abstract}

Keywords Optical coherence tomography $\cdot$ Dual antiplatelet therapy $\cdot$ Biolimus A9 eluting stent $\cdot$ Intra-stent thrombus

\section{Introduction}

Dual antiplatelet therapy (DAPT) with thienopyridine and aspirin is the standard of care for prevention of stent thrombosis [1]. Previous guidelines recommended that DAPT should be continued for at least 12 months in all patients undergoing drug-eluting stent (DES) implantation [2].

Electronic supplementary material The online version of this article (https://doi.org/10.1007/s00380-018-1131-7) contains supplementary material, which is available to authorized users.

Toshiro Shinke

shinke@med.kobe-u.ac.jp

Extended author information available on the last page of the article
However, recent studies have reported that stopping DAPT earlier in selected patients with DES was as safe and efficient as prolonged DAPT [3-8]. Thus, the optimal duration of DAPT remains controversial and the impact of DAPT duration on local vascular reaction has not been elucidated.

NIPPON (Nobori Dual Antiplatelet Therapy as Appropriate Duration) is an open label, randomized multicenter, assessor-blinded, trial designed to demonstrate the non-inferiority of shorter (6-month) DAPT to prolonged (18-month) DAPT after biolimus A9 eluting stent (BES) implantation. This NIPPON main study demonstrated that 6 months of DAPT was not inferior to 18 months of DAPT following implantation of BES in terms of net adverse clinical and cerebrovascular events (all-cause mortality, myocardial infarction, stroke, and major bleeding) [9]. Among the enrolled 
patients, 101 patients were randomly allocated for an optical coherence tomography (OCT) sub-study to assess the local vascular responses to BES implantation. The aim of this study was to compare local vessel healing and in-stent thrombus formation between patients with shorter (6-month) and prolonged (18-month) DAPT.

\section{Materials and methods}

\section{Patient population}

NIPPON is an open-label, randomized, multicenter, assessor-blinded trial designed to demonstrate the non-inferiority of shorter (6-month) DAPT to prolonged (18-month) DAPT after NOBORI stent implantation in patients with coronary artery disease from December 2011 to June 2015 at 130 Japanese institutions (supplementary Appendix 1). Nobori (Terumo Corporation, Tokyo, Japan) is a biolimus A9-eluting stent (BES) with an abluminal-side biodegradable polymer coating that degrades 6-9 months after stent implantation [10]. During hospitalization for percutaneous coronary intervention (PCI), the patients were assigned to 6 or 18 months of DAPT at a 1:1 ratio by central randomization using an interactive web-based system. This study was designed to approximate an all-comers trial with broad inclusion criteria to reflect the real-world clinical setting, and patients with acute myocardial infarction (MI) were also enrolled. The extremely limited exclusion criteria were instent restenosis (bare metal stent or DES) and index PCI for saphenous vein graft disease or unprotected left main trunk disease. The inclusion and exclusion criteria are detailed in supplementary Appendix 2. The study protocol was approved by the institutional review board at each participating center. Written informed consent was obtained from all patients. The study was conducted in accordance with the Declaration of Helsinki and was registered at Clinical Trial Registration (NCT.01514227). A total of 3773 patients were enrolled to NIPPON trial. Among them, 101 patients at 14 Japanese institutions (supplementary Appendix 3) were randomly allocated for OCT sub-study to assess deference of local in-stent thrombus (IS-Th) formation between two groups at 8-12 months after BES implantation.

\section{Dual antiplatelet therapy}

All patients were receiving aspirin (81-162 mg/day). Patients also received ticlopidine $(200 \mathrm{mg} /$ day $)$ or clopidogrel $(75 \mathrm{mg} /$ day $)$ for the assigned duration after PCI. The allowance of DAPT duration in the two groups was defined as NIPPON trial protocol. The following per-protocol analysis was performed in this OCT sub-study: patients in the 6-month DAPT group were referred for analysis when the
DAPT had been stopped until at least 1 month before the follow-up OCT procedure. In the 18-month DAPT group, DAPT had been continued at the time of the OCT follow-up procedure.

\section{OCT examination}

The follow-up OCT examination was performed 8-12 months after BES implantation. The frequency-domain OCT system (C7 Dragonfly ${ }^{\mathrm{TM}}$ or C8 Dragonfly ${ }^{\mathrm{TM}}$; St. Jude Medical, St. Paul, MN, USA) was used in the present study. OCT examination was performed, as previously reported [11]. In the use of the frequency-domain OCT system, a 0.014 -inch standard guide wire was positioned distally in the target vessel and the frequency OCT catheter was advanced to the distal end of the target lesion. The entire length of the region of interest was scanned using the integrated automated pullback device at 10 or $20 \mathrm{~mm} / \mathrm{s}$. For image acquisition, blood in the coronary artery was replaced with iodine contrast media and continuously flushed.

\section{OCT analysis}

Off-line OCT analysis was performed using a dedicated software (LightLab Imaging, Westford, MA, USA). All images were analyzed at every frame in stents by independent investigators, who were blinded to the angiographic and clinical findings. For quantitative analysis, cross-section OCT images were analyzed at $1-\mathrm{mm}$ intervals. As qualitative analysis, IS-Th was defined as a mass protruding beyond the stent strut into the lumen, with significant attenuation behind the mass with a height greater than $250 \mu \mathrm{m}[12,13]$ (Fig. 1). In this present study, we additionally counted the mass with a height of 100-250 $\mu \mathrm{m}$ as micro-in-stent thrombus (MIS-Th) for the detailed assessment of small IS-Th (Fig. 1). Stent struts were classified as uncovered if any part of the strut was visibly exposed to the lumen or covered if a layer of tissue was visible all over the reflecting surfaces. Neointimal thickness was measured from the center reflection of the stent strut to the vessel-lumen border (neointimal surface or strut surface if uncovered) for each stent strut. An uncovered strut was defined as a strut with a neointimal thickness equal to $0 \mu \mathrm{m}$ [14]. The frequency of covered and uncovered struts was calculated as the number of those struts divided by the total number of struts for each stent. A malapposed strut was defined as a distance greater than $140 \mu \mathrm{m}$ between the center reflection of the strut to the vessel wall [15]. The presence of peri-strut low-intensity area (PLIA) was counted per stent. PLIA was defined as a region around stent struts with a homogeneous lower-intensity appearance than surrounding tissue without significant signal attenuation behind the area [16]. 


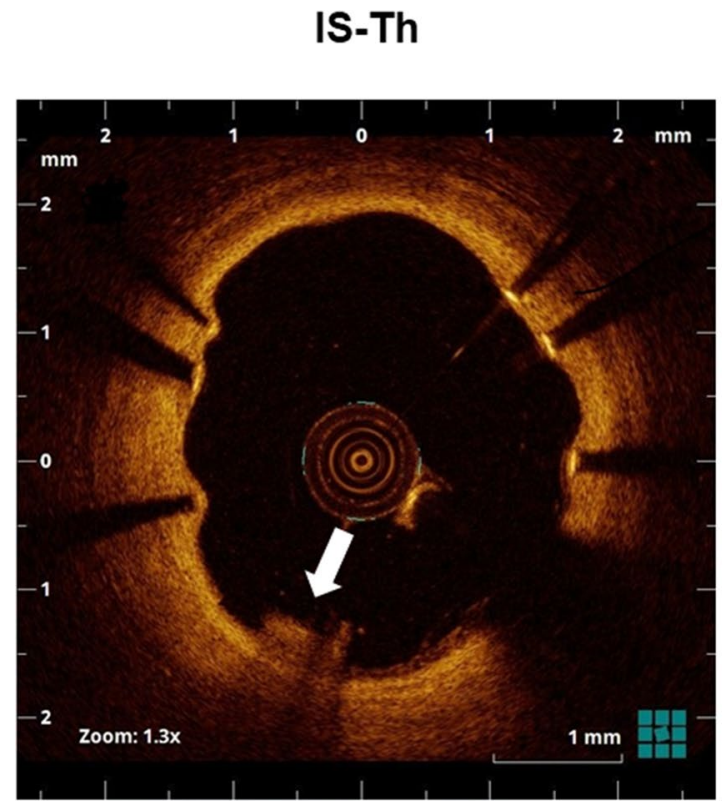

Fig. 1 Representative optical coherence tomographic images of IS-Th and MIS-Th (arrow). IS-Th was defined as a mass protruding beyond the stent strut into the lumen, with significant attenuation behind the

\section{Statistical analysis}

Continuous variables were shown as mean \pm SD and comparisons between two groups were performed using twosample $t$ test or Wilcoxon rank sum test. Discrete variables were presented as frequencies and percentages, and comparisons were performed by Chi-square test or Fisher's exact test. All $P$ values were 2 -sided, and $P<0.05$ was considered to indicate statistical significance. The statistical analysis was conducted using the commercially available SPSS software version 23 (SPSS, Chicago, IL, USA).

Statistical sample size calculation was not done for this sub-study. This is because there was no past report assessing the difference of local IS-Th formation between shorter and prolonged DAPT duration. We enrolled the largest possible number of cases into the OCT sub-study from NIPPON study enrollment.

\section{Results}

\section{Patient and lesion characteristics}

Among 101 patients (135 lesions), 12 patients (23 lesions) were excluded [7 patients (10 lesions), due to deviation from assigned DAPT duration; 5 patients (13 lesions), due to incomplete OCT examination]. Therefore, 89 patients (112 lesions) were enrolled. A total of 41 patients (46 lesions) and 48 patients (66 lesions) were assigned to the
MIS-Th

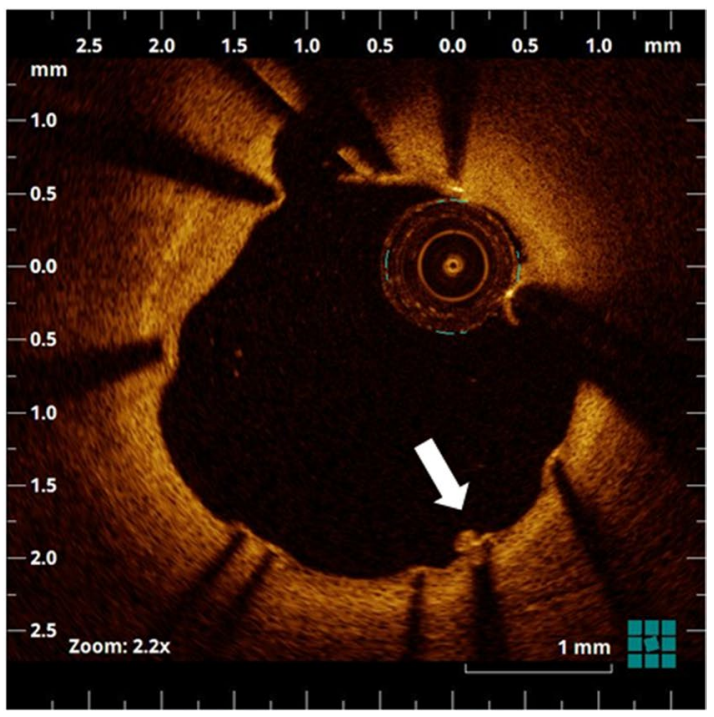

mass with a height over $250 \mu \mathrm{m}$. MIS-Th was defined as a mass with a height of 100-250 $\mu \mathrm{m}$. IS-Th in-stent thrombus, MIS-Th micro instent thrombus

6- and 18-month groups, respectively (Fig. 2). There were no significant differences between the two groups in terms in patient, medication, laboratory data, and lesion characteristics at the OCT follow-up (Tables 1, 2).

\section{OCT characteristics}

Stent, lumen, and neointimal characteristics had no significant difference between the two groups in OCT findings. Except in stent struts characteristics, the percentage of uncovered struts was significantly higher in the 6-month group (Table 3).

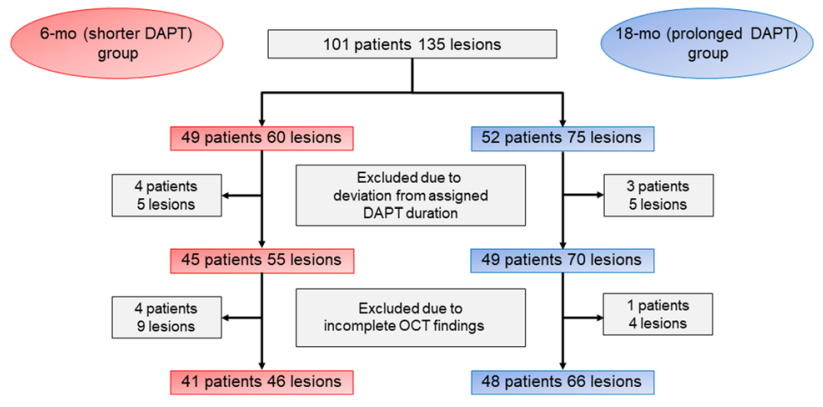

Fig. 2 Study population 
Table 1 Baseline clinical characteristics

\begin{tabular}{|c|c|c|c|}
\hline Variable & 6-month $(n=41)$ & 18-month $(n=48)$ & $P$ value \\
\hline \multicolumn{4}{|l|}{ Clinical characteristics } \\
\hline Age (years) & $67.1 \pm 10.1$ & $66.6 \pm 9.0$ & 0.80 \\
\hline Male & $27(65.9)$ & $36(75.0)$ & 0.34 \\
\hline Diabetes mellitus & $16(39.0)$ & $23(47.9)$ & 0.40 \\
\hline Hypertension & $34(82.9)$ & $31(64.6)$ & 0.052 \\
\hline Dyslipidemia & $28(68.3)$ & $32(66.7)$ & 0.87 \\
\hline Current smoker & $10(24.4)$ & $13(27.1)$ & 0.77 \\
\hline Angina status & & & 0.97 \\
\hline STEMI & $4(9.8)$ & $4(8.3)$ & 1.00 \\
\hline Stable AP & $21(51.2)$ & $23(47.9)$ & 0.76 \\
\hline Unstable AP & $9(22.0)$ & $13(27.1)$ & 0.58 \\
\hline SMI & $6(14.6)$ & $7(14.6)$ & 0.99 \\
\hline \multicolumn{4}{|l|}{ Past medical history } \\
\hline PCI history & $11(26.8)$ & $9(18.8)$ & 0.36 \\
\hline BMS implantation & $8(19.5)$ & $6(12.5)$ & 0.37 \\
\hline DES implantation & $4(9.8)$ & $3(6.3)$ & 0.70 \\
\hline CABG history & $0(0.0)$ & $2(4.2)$ & 0.50 \\
\hline Cerebral infarction & $0(0.0)$ & $1(2.1)$ & 1.00 \\
\hline TIA & $1(2.4)$ & $0(0.0)$ & 0.46 \\
\hline Intracranial bleeding & $0(0.0)$ & $0(0.0)$ & - \\
\hline Gastric ulcer bleeding & $1(2.4)$ & $1(2.1)$ & 1.00 \\
\hline Atrial fibrillation & $0(0.0)$ & $1(2.1)$ & 1.00 \\
\hline PAD & $3(7.3)$ & $0(0.0)$ & 0.09 \\
\hline \multicolumn{4}{|l|}{ Medication } \\
\hline NSAIDs & $1(2.4)$ & $2(4.2)$ & 1.00 \\
\hline Beta blocker & $16(39.0)$ & $13(27.1)$ & 0.23 \\
\hline $\mathrm{ARB}$ & $20(48.8)$ & $25(52.1)$ & 0.76 \\
\hline ACE-I & $6(14.6)$ & $2(4.2)$ & 0.14 \\
\hline Ethyl icosapentate & $1(2.4)$ & $2(4.2)$ & 1.00 \\
\hline PPI & $24(58.5)$ & $31(64.6)$ & 0.56 \\
\hline Steroid & $1(2.4)$ & $0(0.0)$ & 0.46 \\
\hline Statin & $32(78.0)$ & $40(83.3)$ & 0.53 \\
\hline \multicolumn{4}{|l|}{ Laboratory data } \\
\hline Total cholesterol (mg/dL) & $173.0 \pm 30.2$ & $167.4 \pm 31.2$ & 0.44 \\
\hline HDL-cholesterol (mg/dL) & $54.0 \pm 12.0$ & $52.9 \pm 15.6$ & 0.72 \\
\hline LDL-cholesterol (mg/dL) & $96.1 \pm 24.5$ & $95.1 \pm 23.3$ & 0.86 \\
\hline $\mathrm{Hb}_{\mathrm{A} 1 \mathrm{C}}(\%)$ & $6.09 \pm 0.63$ & $6.50 \pm 1.19$ & 0.06 \\
\hline Creatinine (mg/dL) & $0.85 \pm 0.18$ & $0.83 \pm 0.22$ & 0.76 \\
\hline
\end{tabular}

Values are presented as mean \pm SD or absolute numbers $(\%)$

$A C E-I$ angiotensin converting enzyme inhibitor, $A P$ angina pectoris, $A R B$ angiotensin receptor blocker, $B M S$ bare metal stent, $C A B G$ coronary artery bypass graft, $D E S$ drug-eluting stent, $N S A I D s$ nonsteroidal anti-inflammatory drugs, $P A D$ peripheral artery disease, $P C I$ percutaneous coronary intervention, $P P I$ proton pump inhibitor, SMI silent myocardial ischemia, STEMI ST elevation myocardial infarction, TIA transient ischemic attack

\section{IS-Th characteristics}

Among 89 patients (112 lesions), IS-Th was identified in 11 lesions $(9.8 \%)$. The presence and number of IS-Th had no significant difference between the two groups. In addition, the presence and number of MIS-Th had no significant difference between the two groups (Table 4, Figs. 3, $4)$. 
Table 2 Baseline lesion characteristics

\begin{tabular}{llll}
\hline Variable & 6-month $(n=46)$ & 18-month $(n=66)$ & $P$ value \\
\hline $\begin{array}{l}\text { Duration between PCI and OCT follow- } \\
\text { up (days) }\end{array}$ & $293.2 \pm 49.9$ & $278.0 \pm 41.4$ & 0.093 \\
Lesion location & & & 0.35 \\
Left anterior descending artery & $30(65.2)$ & $34(51.5)$ & \\
Left circumflex artery & $7(15.2)$ & $13(19.7)$ & \\
Right coronary artery & $9(19.6)$ & $19(28.8)$ & 0.55 \\
Stent size (mm) & $3.04 \pm 0.40$ & $3.08 \pm 0.34$ & 0.24 \\
Stent length (mm) & $23.4 \pm 12.7$ & $26.6 \pm 14.9$ & \\
\hline
\end{tabular}

Values are presented as mean \pm SD or absolute numbers (\%)

$O C T$ optical coherence tomography, $P C I$ percutaneous coronary intervention

\begin{tabular}{|c|c|c|c|}
\hline Variable & 6-month $(n=46)$ & 18-month $(n=66)$ & $P$ value \\
\hline \multicolumn{4}{|l|}{ Stent characteristics } \\
\hline Average stent area $\left(\mathrm{mm}^{2}\right)$ & $7.29 \pm 2.97$ & $7.46 \pm 2.56$ & 0.75 \\
\hline Minimum stent area $\left(\mathrm{mm}^{2}\right)$ & $5.89 \pm 2.50$ & $5.67 \pm 2.30$ & 0.63 \\
\hline Maximum stent area $\left(\mathrm{mm}^{2}\right)$ & $8.82 \pm 3.60$ & $9.16 \pm 3.01$ & 0.60 \\
\hline Average stent diameter (mm) & $2.98 \pm 0.58$ & $3.03 \pm 0.51$ & 0.67 \\
\hline Minimum stent diameter (mm) & $2.49 \pm 0.54$ & $2.43 \pm 0.52$ & 0.52 \\
\hline Maximum stent diameter (mm) & $3.51 \pm 0.74$ & $3.64 \pm 0.65$ & 0.33 \\
\hline \multicolumn{4}{|l|}{ Lumen characteristics } \\
\hline Average lumen area $\left(\mathrm{mm}^{2}\right)$ & $6.84 \pm 2.94$ & $6.85 \pm 2.54$ & 0.99 \\
\hline Minimum lumen area $\left(\mathrm{mm}^{2}\right)$ & $5.27 \pm 2.60$ & $5.03 \pm 2.37$ & 0.61 \\
\hline Maximum lumen area $\left(\mathrm{mm}^{2}\right)$ & $8.61 \pm 3.51$ & $8.69 \pm 2.97$ & 0.89 \\
\hline Ratio (min/max lumen area) & $0.61 \pm 0.15$ & $0.58 \pm 0.15$ & 0.33 \\
\hline \multicolumn{4}{|l|}{ Neointimal characteristics } \\
\hline Average neointimal area $\left(\mathrm{mm}^{2}\right)$ & $0.50 \pm 0.33$ & $0.63 \pm 0.36$ & 0.06 \\
\hline$\%$ neointimal area $(\%)$ & $7.97 \pm 6.22$ & $9.41 \pm 5.35$ & 0.19 \\
\hline Average neointimal thickness (mm) & $0.08 \pm 0.03$ & $0.09 \pm 0.03$ & 0.40 \\
\hline Peri-strut law intensity area (\%) & $19(41.3)$ & $37(56.1)$ & 0.12 \\
\hline \multicolumn{4}{|l|}{ Stent struts characteristics } \\
\hline Total no of cross sections $(n)$ & $25.0 \pm 12.8$ & $27.3 \pm 13.7$ & 0.38 \\
\hline Total no of struts $(n)$ & $252.4 \pm 138.7$ & $277.1 \pm 187.2$ & 0.45 \\
\hline No of uncovered struts $(n)$ & $11.57 \pm 12.71$ & $8.36 \pm 14.85$ & 0.24 \\
\hline$\%$ of uncovered struts (\%) & $4.70 \pm 4.92$ & $2.59 \pm 2.45$ & 0.009 \\
\hline No of malapposed struts $(n)$ & $1.13 \pm 3.38$ & $0.42 \pm 1.27$ & 0.18 \\
\hline$\%$ of malapposed struts (\%) & $0.44 \pm 1.20$ & $0.13 \pm 0.39$ & 0.10 \\
\hline
\end{tabular}

Values are presented as mean \pm SD or absolute numbers (\%)
Table 3 Optical coherence tomography findings

\section{Discussion}

The NIPPON OCT sub-study was a multicenter, randomized control trial to evaluate the difference of IS-Th formation between shorter and prolonged DAPT duration after BES implantation and was first to demonstrate that the incidence of IS-Th formation at mid-term follow-up was equivalent between the two groups. BES has an abluminal-side biodegradable polymer coating that degrades
6-9 months after stent implantation [10]. Several studies reported that BES had similar stent coverage and apposition and low rate of stent thrombosis as compared to everolimus-eluting stent at mid-term after stent implantation $[17,18]$.

The frequency of IS-Th at mid-term OCT findings after BES implantation was reported in several studies. The range of the frequency was $7-10 \%$ in those studies [19, 20]. In the current study, 11 lesions $(9.8 \%)$ had IS-Th, and the rate corresponded to these previous studies. This 
Table 4 IS-Th characteristics

\begin{tabular}{llll}
\hline Variable & 6 -month $(n=46)$ & 18 -month $(n=66)$ & $P$ value \\
\hline $\begin{array}{l}\text { IS-Th } \\
\text { The presence of thrombus }\end{array}$ & $5(10.9)$ & $6(9.1)$ & 0.76 \\
The number of thrombi & & & 0.70 \\
0 & $41(89.1)$ & $61(92.4)$ & \\
1 & $4(8.7)$ & $5(7.6)$ & 0.75 \\
2 & $1(2.2)$ & $0(0.0)$ & 0.085 \\
MIS-Th & & & \\
The presence of thrombus & $8(17.4)$ & $10(15.2)$ & \\
The number of thrombi & & $56(84.8)$ & \\
0 & $38(82.6)$ & $9(13.6)$ & \\
1 & $3(6.5)$ & $0(1.5)$ & \\
2 & $4(8.7)$ & $1(2.2)$ &
\end{tabular}

Values are presented as absolute numbers (\%)

$I S$-Th in-stent thrombus, MIS-Th micro in-stent thrombus

Fig. 3 Association between dual antiplatelet therapy duration and in-stent thrombus formation
Fig. 4 Association between dual antiplatelet therapy duration and micro in-stent thrombus formation

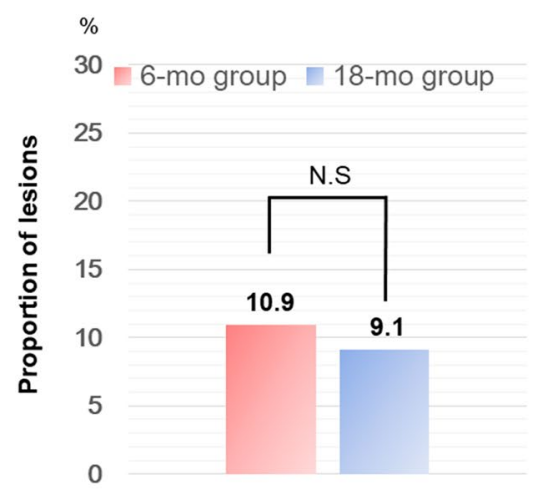

The presence of IS-Th

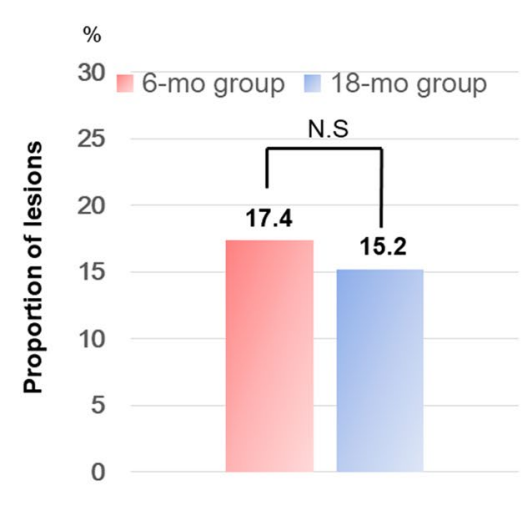

The presence of MIS-Th
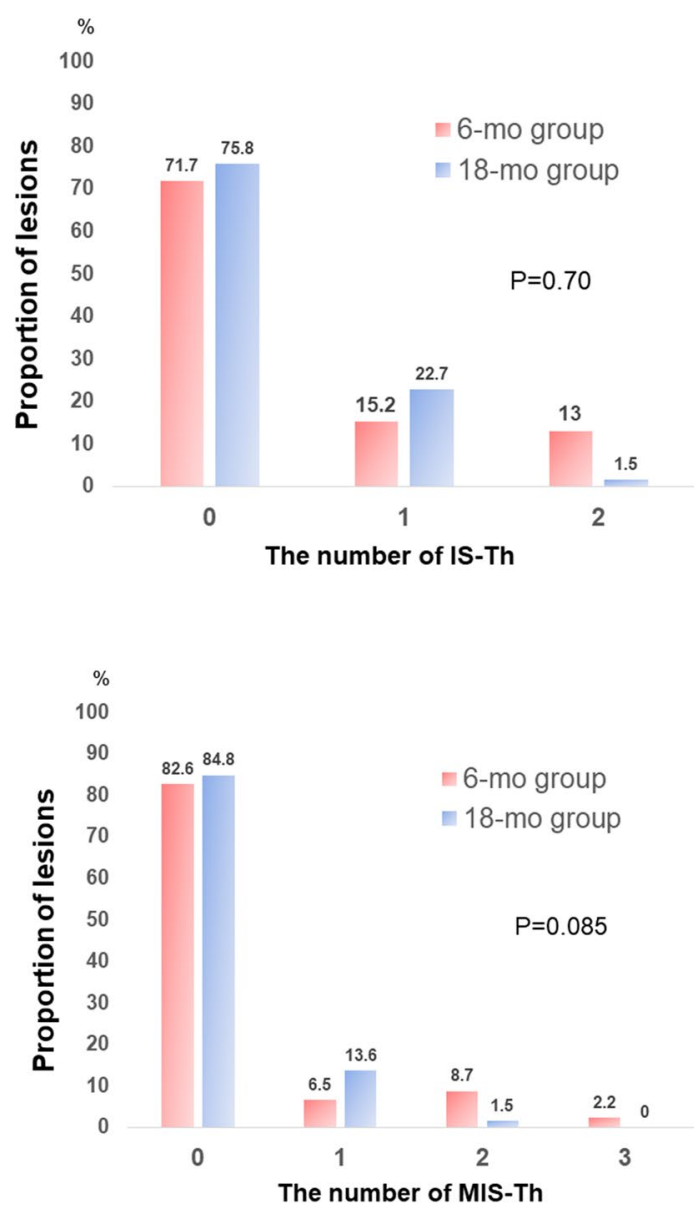

study also showed that the presence and number of IS-Th had no significant difference between the two groups. This result may support previous studies that demonstrated the non-inferiority of short-term DAPT [3-8]. Konishi et al.
[19]. has reported that patients with BES implantation achieved favorable vessel healing at 6 months without delayed adverse reaction for up to 12 months. 
In the current study, uncovered strut was incidentally higher in the 6-month group than in the 18-month group, but the percentage of malapposed strut was not different. A previous autopsy study evaluating first-generation DESs have shown that an uncovered strut could be a substrate for thrombus formation, which can potentially lead to a thrombotic event [21]. However, a recent clinical trial using OCT for assessing vascular response to DESs has suggested that an uncovered strut, as marker of incomplete vessel healing, may not be directly associated with adverse clinical outcome in second-generation DESs [20]. Regarding BES, stopping DAPT at 6 months does not appear to pose a high risk of provoking IS-Th due to favorable vessel healing during the early phase after stent implantation.

The latest American College of Cardiology/American Heart Association guideline, which is focused on the update on duration of DAPT in patients with coronary artery disease, recommends that patients with stable ischemic heart disease (SIHD) treated with DAPT after DES implantation should undergo P2Y12 inhibitor therapy with clopidogrel for at least 6 months [22]. Identically, European Society of Cardiology guidelines described that DAPT is indicated for 6 months after DES implantation in patients with SIHD [23]. The present study supports these criteria from the viewpoint of local thrombus formation at mid-term OCT findings.

\section{Limitations}

This study has several limitations. First, this was not a double-blind trial; thus, selection bias cannot be excluded. Second, the present study may be not adequately powered to calculate the difference of IS-Th formation due to limited sample size. Despite our plan to enroll 100 patients undergoing DAPT, only 89 patients were finally enrolled in the present study. This is because of the reduced number of patients and the small difference in the primary end-point between the two DAPT groups in the main NIPPON trial. Third, antiplatelet therapy was limited to clopidogrel and ticlopidine in our study; thus, the use of more potent antiplatelet agents may have led to different conclusions. Fourth, in the present study, follow-up OCT was performed at 8-12 months after stent implantation. Therefore, there was only $2-6$ months deference of the DAPT duration between the two groups. Longer duration after the cessation or continuation of DAPT may be required to estimate the impact of DAPT duration on IS-Th formation. Fifth, the result of the present study suggested that shorter DAPT duration did not provoke IS-Th formation, however, this study was underpowered to show the association between IS-Th formation and clinical events due to small sample size. Finally, vascular healing response depends on the underlying plaque morphology before stenting [24]. More specifically, vulnerable plaque characteristics in ACS can significantly influence vascular healing after BES implantation. More information regarding plaque morphology at the index procedure should be required.

\section{Conclusions}

This NIPPON OCT sub-study suggested that a shortened DAPT duration does not appear to provoke IS-Th formation after cessation of one antiplatelet regimen at mid-term OCT follow-up. These results were in line with the main NIPPON study which demonstrated the non-inferiority of 6-month DAPT compared with 18-month DAPT.

Acknowledgements All the authors have participated in the conceptual formulation of the study, data collection, and manuscript preparation. Drs. Nakamura, Iijma, Ako, Shinke, and Yokoi established the study design and conception and interpreted the data. Dr. Kuroda drafted the manuscript, and Dr Shinke contributed to revising it critically for important intellectual content. Dr Hamasaki contributed to the statistical analysis.

Funding This research was supported by the Associations for Establishment of Evidence in Interventions (2-5-3 New-Hamamatsu building, Hamamatsucho, Minato-ku, Tokyo 105-0013, Japan).

\section{Compliance with ethical standards}

Conflict of interest Dr. Nakamura has received research grant support and honoraria from Terumo Corp, Sanofi, and Daiichi Sankyo. Dr Shinke has received research grant support from Terumo Corp and honoraria from Terumo Corp, Daiichi Sankyo, and Sanofi. Dr. Otake has received research grant support and honoraria from Terumo Corp Dr Yokoi received honoraria from Terumo and Daiichi Sankyo. Dr Ochiai has received expert witness fee from Terumo Corp. Dr Kawaguchi received honoraria from Terumo Corp. All authors have no commercial associations that might pose a conflict of interest in connection with the manuscript.

Open Access This article is distributed under the terms of the Creative Commons Attribution 4.0 International License (http://creativecommons.org/licenses/by/4.0/), which permits unrestricted use, distribution, and reproduction in any medium, provided you give appropriate credit to the original author(s) and the source, provide a link to the Creative Commons license, and indicate if changes were made.

\section{References}

1. King SB 3rd, Smith SC Jr., Hirshfeld JW Jr., Jacobs AK, Morrison DA, Williams DO; 2005 WRITING COMMITTEE MEMBERS, Feldman TE, Kern MJ, O'Neill WW, Schaff HV, Whitlow PL, Adams CD, Anderson JL, Buller CE, Creager MA, Ettinger SM, Halperin JL, Hunt SA, Krumholz HM, Kushner FG, Lytle BW, Nishimura R, Page RL, Riegel B, Tarkington LG, Yancy CW (2008) 2007 Focused Update of the ACC/AHA/SCAI 2005 Guideline Update for Percutaneous Coronary Intervention: a report of the American College of Cardiology/American Heart Association Task Force on Practice Guidelines: 2007 Writing 
Group to Review New Evidence and Update the ACC/AHA/SCAI 2005 Guideline Update for Percutaneous Coronary Intervention, Writing on Behalf of the 2005 Writing Committee. Circulation 117:261-295

2. Levine GN, Bates ER, Blankenship JC, Bailey SR, Bittl JA, Cercek B, Chambers CE, Ellis SG, Guyton RA, Hollenberg SM, Khot UN, Lange RA, Mauri L, Mehran R, Moussa ID, Mukherjee D, Nallamothu BK, Ting HH (2011) 2011 ACCF/AHA/SCAI Guideline for Percutaneous Coronary Intervention: executive summary: a report of the American College of Cardiology Foundation/ American Heart Association Task Force on Practice Guidelines and the Society for Cardiovascular Angiography and Interventions. Circulation 124:2574-2609

3. Gwon HC, Hahn JY, Park KW, Song YB, Chae IH, Lim DS, Han KR, Choi JH, Hoi SH, Kang HJ, Koo BK, Ahn T, Yoon JH, Jeong MH, Hong TJ, Chung WY, Choi YJ, Hur SH, Kwon HM, Jeon DW, Kim BO, Park SH, Lee NH, Jeon HK, Jang Y, Kim HS (2012) Six-month versus 12-month dual antiplatelet therapy after implantation of drug-eluting stents: the efficacy of xience/promus versus cypher to reduce late loss after stenting (EXCELLENT) randomized, multicenter study. Circulation 125:505-513

4. Kim BK, Hong MK, Shin DH, Nam CM, Kim JS, Ko YG, Choi D, Kang TS, Park BE, Kang WC, Lee SH, Yoon JH, Hong BK, Kwon HM, Jang Y (2012) A new strategy for discontinuation of dual antiplatelet therapy: the RESET Trial (REal Safety and Efficacy of 3-month dual antiplatelet Therapy following endeavor zotarolimus-eluting stent implantation). J Am Coll Cardiol 60:1340-1348

5. Valgimigli M, Campo G, Monti M, Vranckx P, Percoco G, Tumscitz C, Castriota F, Colombo F, Tebaldi M, Fuca G, Kubbajeh M, Cangiano E, Minarelli M, Scalone A, Cavazza C, Frangione A, Borghesi M, Marchesini J, Parrinello G, Ferrari R (2012) Short- versus long-term duration of dual-antiplatelet therapy after coronary stenting: a randomized multicenter trial. Circulation 125:2015-2026

6. Feres F, Costa RA, Abizaid A, Leon MB, Marin-Neto JA, Botelho RV, King SB 3rd, Negoita Liu M, de Paula JE, Mangione JA, Meireles GX, Castello HJ Jr, Nicolela EL Jr, Perin MA, Devito FS, Labrunie A, Salvadori D Jr, Gusmao M, Staico R, Costa JR Jr, de Castro JP, Abizaid AS, Bhatt DL (2013) Three vs twelve months of dual antiplatelet therapy after zotarolimus-eluting stents: the OPTIMIZE randomized trial. JAMA 310:2510-2522

7. Colombo A, Chieffo A, Frasheri A, Garbo R, Masotti-Centol M, Salvatella N, Oteo Dominguez JF, Steffanon L, Tarantini G, Presbitero P, Menozzi A, Pucci E, Mauri J, Cesana BM, Giustino G, Sardella G (2014) Second-generation drug-eluting stent implantation followed by 6 - versus 12 -month dual antiplatelet therapy: the SECURITY randomized clinical trial. J Am Coll Cardiol 64:2086-2097

8. Schulz-Schupke S, Byrne RA, Ten Berg JM, Neumann FJ, Han Y, Adriaenssens T, Tolg R, Seyfarth M, Maeng M, Zrenner B, Jacobshagen C, Mudra H, von Hodenberg E, Wohrle J, Angiolillo DJ, von Merzljak B, Rifatov N, Kufner S, Morath T, Feuchtenberger A, Ibrahim T, Janssen PW, Valina C, Li Y, Desmet W, AbdelWahab M, Tiroch K, Hengstenberg C, Bernlochner I, Fischer M, Schunkert H, Laugwitz KL, Schomig A, Mehilli J, Kastrati A (2015) ISAR-SAFE: a randomized, double-blind, placebo-controlled trial of 6 vs. 12 months of clopidogrel therapy after drugeluting stenting. Eur Heart J 36:1252-1263

9. Nakamura M, Iijima R, Ako J, Shinke T, Okada H, Ito Y, Ando K, Anzai H, Tanaka H, Ueda Y, Takiuchi S, Nishida Y, Ohira H, Kawaguchi K, Kadotani M, Niinuma H, Omiya K, Morita T, Zen K, Yasaka Y, Inoue K, Ishiwata S, Ochiai M, Hamasaki T, Yokoi H (2017) Dual antiplatelet therapy for 6 versus 18 months after biodegradable polymer drug-eluting stent implantation. JACC Cardiovasc Interv 10:1189-1198
10. Chevalier B, Silber S, Park SJ, Garcia E, Schuler G, Suryapranata H, Koolen J, Hauptmann KE, Wijns W, Morice MC, Carrie D, van Es GA, Nagai H, Detiege D, Paunovic D, Serruys PW (2009) Randomized comparison of the Nobori Biolimus A9-eluting coronary stent with the Taxus Liberte paclitaxel-eluting coronary stent in patients with stenosis in native coronary arteries: the NOBORI 1 trial-Phase 2. Circ Cardiovasc Interv 2:188-195

11. Matsumoto D, Shite J, Shinke T, Otake H, Tanino Y, Ogasawara D, Sawada T, Paredes OL, Hirata K, Yokoyama M (2007) Neointimal coverage of sirolimus-eluting stents at 6-month follow-up: evaluated by optical coherence tomography. Eur Heart J 28:961-967

12. Kume T, Akasaka T, Kawamoto T, Ogasawara Y, Watanabe N, Toyota E, Neishi Y, Sukmawan R, Sadahira Y, Yoshida K (2006) Assessment of coronary arterial thrombus by optical coherence tomography. Am J Cardiol 97:1713-1717

13. Jang IK, Tearney GJ, MacNeill B, Takano M, Moselewski F, Iftima N, Shishkov M, Houser S, Aretz HT, Halpern EF, Bouma BE (2005) In vivo characterization of coronary atherosclerotic plaque by use of optical coherence tomography. Circulation 111:1551-1555

14. Otake H, Shite J, Ako J, Shinke T, Tanino Y, Ogasawara D, Sawada T, Miyoshi N, Kato H, Koo BK, Honda Y, Fitzgerald PJ, Hirata K (2009) Local determinants of thrombus formation following sirolimus-eluting stent implantation assessed by optical coherence tomography. JACC Cardiovasc Interv 2:459-466

15. Konishi A, Shinke T, Otake H, Takaya T, Osue T, Kinutani H, Kuroda M, Takahashi H, Terashita D, Shite J, Hirata K (2015) Serial optical coherence tomography evaluation at 6,12 , and 24 months after biolimus A9-eluting biodegradable polymer-coated stent implantation. Can J Cardiol 31:980-988

16. Otake H, Shite J, Ikeno F, Shinke T, Teramoto T, Miyoshi N, Ako J, Honda Y, Fitzgerald PJ, Hirata K (2012) Evaluation of the peri-strut low intensity area following sirolimus- and paclitaxel-eluting stents implantation: insights from an optical coherence tomography study in humans. Int J Cardiol 157:38-42

17. Natsuaki M, Kozuma K, Morimoto T, Kadota K, Muramatsu T, Nakagawa Y, Akasaka T, Igarashi K, Tanabe K, Morino Y, Ishikawa T, Nishikawa H, Awata M, Abe M, Okada H, Takatsu Y, Ogata N, Kimura K, Urasawa K, Tarutani Y, Shiode N, Kimura $\mathrm{T}$ (2013) Biodegradable polymer biolimus-eluting stent versus durable polymer everolimus-eluting stent: a randomized, controlled, noninferiority trial. J Am Coll Cardiol 62:181-190

18. Tada T, Kastrati A, Byrne RA, Schuster T, Cuni R, King LA, Cassese S, Joner M, Pache J, Massberg S, Schomig A, Mehilli J (2014) Randomized comparison of biolimus-eluting stents with biodegradable polymer versus everolimus-eluting stents with permanent polymer coatings assessed by optical coherence tomography. Int J Cardiovasc Imaging 30:495-504

19. Konishi A, Shinke T, Otake H, Takaya T, Nakagawa M, Inoue T, Hariki H, Osue T, Taniguchi Y, Iwasaki M, Nishio R, Hiranuma N, Kinutani H, Kuroda M, Takahashi H, Terashita D, Shite J, Hirata K (2014) Favorable vessel healing after nobori biolimus A9-eluting stent implantation-6- and 12-month follow-up by optical coherence tomography. Circ J 78:1882-1890

20. Kubo T, Akasaka T, Kozuma K, Kimura K, Fusazaki T, Okura H, Shinke T, Ino Y, Hasegawa T, Takashima H, Takamisawa I, Yamaguchi H, Igarashi K, Kadota K, Tanabe K, Nakagawa Y, Muramatsu T, Morino Y, Kimura T (2014) Vascular response to drug-eluting stent with biodegradable vs. durable polymer. Optical coherence tomography substudy of the NEXT. Circ J 78:2408-2414

21. Finn AV, Joner M, Nakazawa G, Kolodgie F, Newell J, John MC, Gold HK, Virmani R (2007) Pathological correlates of late drug-eluting stent thrombosis: strut coverage as a marker of endothelialization. Circulation 115:2435-2441 
22. Levine GN, Bates ER, Bittl JA, Brindis RG, Fihn SD, Fleisher LA, Granger CB, Lange RA, Mack MJ, Mauri L, Mehran R, Mukherjee D, Newby LK, O'Gara PT, Sabatine MS, Smith PK, Smith SC Jr (2016) 2016 ACC/AHA Guideline Focused Update on duration of dual antiplatelet therapy in patients with coronary artery disease: a Report of the American College of Cardiology/American Heart Association Task Force on Clinical Practice Guidelines. J Am Coll Cardiol 68(10):1082-1115

23. Windecker S, Kolh P, Alfonso F, Collet JP, Cremer J, Falk V, Filippatos G, Hamm C, Head SJ, Juni P, Kappetein AP, Kastrati A, Knuuti J, Landmesser U, Laufer G, Neumann FJ, Richter DJ, Schauerte P, Sousa Uva M, Stefanini GG, Taggart DP, Torracca L,
Valgimigli M, Wijns W, Witkowski A (2014) 2014 ESC/EACTS Guidelines on myocardial revascularization: the Task Force on Myocardial Revascularization of the European Society of Cardiology (ESC) and the European Association for Cardio-Thoracic Surgery (EACTS) Developed with the special contribution of the European Association of Percutaneous Cardiovascular Interventions (EAPCI). Eur Heart J 35:2541-2619

24. Nakazawa G, Finn AV, Joner M, Ladich E, Kutys R, Mont EK, Gold HK, Burke AP, Kolodgie FD, Vrimani R (2008) Delayed arterial healing and increased late stent thrombosis at culprit sites after drug-eluting stent placement for acute myocardial infarction patients: an autopsy study. Circulation 118:1138-1145

\section{Affiliations}

Koji Kuroda ${ }^{1} \cdot$ Toshiro Shinke $^{1}$ (1) $\cdot$ Hiromasa Otake $^{1} \cdot$ Hiroto Kinutani $^{1} \cdot$ Raisuke lijima $^{2} \cdot$ Junya Ako $^{3}$. Hisayuki Okada ${ }^{4} \cdot$ Yoshiaki Ito $^{5} \cdot \mathrm{Kenji} \mathrm{Ando}^{6} \cdot$ Hitoshi Anzai $^{7} \cdot$ Hiroyuki Tanaka $^{8} \cdot$ Yasunori Ueda $^{9} \cdot$ Shin Takiuchi $^{10}$. Yasunori Nishida ${ }^{11}$. Hiroshi Ohira ${ }^{12} \cdot$ Katsuhiro Kawaguchi $^{13} \cdot$ Makoto Kadotani $^{14} \cdot$ Hiroyuki Niinuma $^{15}$. Kazuto Omiya ${ }^{16} \cdot$ Takashi Morita $^{17} \cdot$ Kan Zen $^{18}$. Yoshinori Yasaka ${ }^{19} \cdot$ Kenji Inoue $^{20}$. Sugao Ishiwata ${ }^{21}$. Masahiko Ochiai ${ }^{22} \cdot$ Toshimitsu Hamasaki $^{23} \cdot$ Kazushi Urasawa $^{24} \cdot$ Toru Kataoka $^{25} \cdot$ Minoru Yoshiyama $^{26}$. Kenshi Fujii ${ }^{27} \cdot$ Takumi Inoue $^{28} \cdot$ Masahito Kawata $^{29} \cdot$ Hiroyoshi Yokoi $^{30} \cdot$ Masato Nakamura $^{2} \cdot$ On behalf of the NIPPON investigators

1 Division of Cardiovascular, Department of Cardiology, Kobe University Graduate School of Medicine, 7-5-1 Kusunoki-cho, Chuo-ku, Kobe, Hyogo 650-0017, Japan

2 Division of Cardiovascular Medicine, Toho University Ohashi Medical Center, Tokyo, Japan

3 Department of Cardiovascular Medicine, Kitasato University Hospital, Sagamihara, Japan

4 Department of Cardiology, Seirei Hamamatsu General Hospital, Hamamatsu, Japan

5 Division of Cardiology, Saiseikai Yokohama-City Eastern Hospital, Yokohama, Japan

6 Department of Cardiology, Kokura Memorial Hospital, Kitakyushu, Japan

7 Cardiology Department, Ota Memorial Hospital, Ota, Japan

8 Department of Cardiology, Tokyo Metropolitan Tama Medical Center, Tokyo, Japan

9 Cardiovascular Division, National Hospital Organization Osaka National Hospital, Osaka, Japan

10 Department of Cardiology, Higashi Takarazuka Satoh Hospital, Takarazuka, Japan

11 Department of Cardiovascular Medicine, Takai Hospital, Tenri, Japan

12 Department of Cardiology, Edogawa Hospital, Tokyo, Japan

13 Department of Cardiology, Komaki City Hospital, Komaki, Japan

14 Department of Cardiology, Kakogawa Central City Hospital, Kakogawa, Japan

15 Department of Cardiology, St. Luke's International Hospital, Tokyo, Japan

16 Division of Cardiology, St. Marianna University School of Medicine Yokohama City Seibu Hospital, Yokohama, Japan
17 Division of Cardiology, Osaka General Medical Center, Osaka, Japan

18 Department of Cardiovascular Medicine, Omihachiman Community Medical Center, Omihachiman, Japan

19 Department of Cardiology, Hyogo Brain and Heart Center, Himeji, Japan

20 Department of Cardiology, Juntendo University Nerima Hospital, Tokyo, Japan

21 Division of Cardiovascular Center, Toranomon Hospital, Tokyo, Japan

22 Division of Cardiology and Cardiac Catheterization Laboratories, Showa University Northern Yokohama Hospital, Yokohama, Japan

23 Department of Data Science, National Cerebral and Cardiovascular Center, Suita, Japan

24 Cardiovascular Center, Tokeidai Memorial Hospital, Sapporo, Japan

25 Department of Cardiovascular Medicine, Bell Land General Hospital, Kyoto, Japan

26 Cardiovascular Medicine, Osaka City University Hospital, Osaka, Japan

27 Cardiovascular Center, Sakurabashi Watanabe Hospital, Osaka, Japan

28 Department of Cardiology, Hyogo Prefectural Awaji Medical Center, Sumoto, Japan

29 Department of Cardiology, Akashi Medical Center, Akashi, Japan

30 Department of Cardiovascular Medicine Center, Fukuoka Sanno Hospital, Fukuoka, Japan 